\title{
IV
}

\section{AS COMUNIDADES TERAPÊUTICAS BRASILEIRAS E A PANDEMIA DO NOVO CORONAVÍRUS ${ }^{*}$}

\author{
Tathiana Meyre da Silva Gomes \\ Rachel Gouveia Passos \\ Jessica Souza de Farias \\ Giulia de Castro Lopes de Araujo
}

\section{Introdução}

Nenhuma sociedade que esquece a arte de questionar pode esperar respostas para os problemas que a afligem.

(Zygmunt Bauman)

A chegada do novo coronavírus (2019-nCoV) no país, com a confirmação do primeiro caso em 26/02/2020, no estado de São Paulo (BRASIL, 2020), vem impondo alterações na organização da vida de todos nós. Quarentena ${ }^{1}$, isolamento social ${ }^{2}$ e lockdown ${ }^{3}$ foram termos que passaram a fazer parte do cotidiano da maior parte da população, ao menos no plano do discurso. A quarentena para atividades consideradas não essenciais assim como a possibilidade de um fechamento total ocasionou medo, incerteza, insegurança, desconforto (especialmente entre os trabalhadores pobres) e forjou uma nova forma de convívio social em grande parte do país. Mensagens

\footnotetext{
*DOI - 10.29388/978-65-86678-44-4-0-f.117-138

${ }^{1}$ Restrição de atividades ou separação de pessoas que foram presumivelmente expostas a uma doença contagiosa, mas que não estão doentes (porque não foram infectadas ou porque estão no período de incubação).

${ }^{2}$ Medida que visa separar as pessoas doentes (sintomáticos respiratórios, casos suspeitos ou confirmados de infecção por coronavírus) das não doentes, para evitar a propagação do vírus.

3 Intervenção aplicada a uma comunidade, uma cidade ou uma região, com o objetivo de restringir a interação entre as pessoas e interromper qualquer atividade por um curto período de tempo, com exceção de saídas para atividades básicas como comprar mantimentos ou remédios.
} 
difusas e contraditórias emitidas pelas autoridades em âmbito federal, estadual e municipal reforçaram este cenário de incertezas e, ao que tudo indica, contribuíram para uma saída mais lenta da crise sanitária no país.

No momento em que este artigo é escrito o mundo registra um total de 889.842 mortes pelo novo coronavírus e 27.200 .943 pessoas contaminadas. A América Latina e Caribe, região do mundo mais afetada, os números chegam a 290.000 mortes e mais de 7.700 .000 de casos. No Brasil os dados somam 126.960 mortes e 4.147 .794 contaminados. Estes números alarmantes expressam os dados oficiais. Contudo, sabe-se que num cenário de pandemia não é incomum haver uma subnotificação de casos decorrentes de múltiplos fatores, dentre eles: a velocidade de contaminação e óbito, a dificuldade de acesso, pelas pessoas infectadas, aos serviços de saúde públicos colapsados e, em alguns países como o Brasil, a não realização de testes em larga escala.

Quanto a subnotificação de casos no país, estudos realizados pela Universidade de São Paulo (USP) e pela Universidade de Brasília (UnB) estimam que os casos notificados pelo Ministério da Saúde chegam a ser 15 vezes menores do que os ocorridos (PASSOS, 2020). Inferimos que isto se deve, sobretudo, pela falta de testagem. Neste cenário houve, ainda, a aprovação da Portaria Conjunta nำ1, de 30 de março de 2020, que autoriza procedimentos especiais de cremação e sepultamento de corpos durante o período da pandemia, reforçando a imprecisão acerca do diagnóstico para o novo coronavírus na ocasião da morte.

Inicialmente o Ministério da Saúde (MS) seguiu os protocolos sugeridos pela Organização Mundial da Saúde (OMS) para controle da epidemia, o isolamento social. Após duas mudanças sucessivas no comando da pasta e de sua militarização, o MS rumou para outra direção na tentativa de combate à doença: o discurso do isolamento foi sendo enfraquecido, recrudescendo a pressão sobre os governadores para viabilizarem a flexibilização em seus estados, a despeito da curva de contaminação e óbito em ascensão no país.

É importante destacar que a medida de isolamento social, adotada na maior parte dos países que foram atingidos pela pandemia, vem sendo alvo de polêmicas no Brasil no interior do próprio 
Governo Federal. Este adotou, recentemente, estratégia distinta da maior parte dos países e recomendada pela Organização das Nações Unidas (ONU) e deixou de sustentar o isolamento social para contenção da pandemia, exceto no caso dos pacientes considerados como grupo de risco (idosos e pessoas com comorbidade), argumentando tratar-se de uma "gripezinha" (PASSOS, 2020) que não pode comprometer a economia do país. Ao que tudo parece indicar, preocupações com a crise de ordem economia, decorrência esperada da conjuntura atual, tem tomado mais espaço no governo brasileiro do que a crise sanitária.

A chegada da pandemia no país desnudou as desigualdades socioeconômicas existentes, aprofundando-as ainda mais. Trata-se de uma grave crise sanitária que atinge de maneira distinta a população do país e uma das consequências das medidas que envolvem a contenção desta crise ocorre na esfera econômica. A experiência da doença, a vivência da morte de entes queridos, o isolamento social e a crise econômica não podem ser homogeneizada num país com tamanha desigualdade como o Brasil. Ao contrário, ela repõe e aprofunda ainda mais essas desigualdades.

Por aqui, país marcado em sua formação social pela modernização conservadora, a crise sanitária teve rápido impacto econômico e social, como demonstram os dados do Instituto Brasileiro de Geografia e Estatística (IBGE) quando se trata da taxa de desocupação do segundo trimestre do ano de 2020: representou $12 \%$ para homens e $14 \%$ para mulheres, ainda que estas correspondam a $53 \%$ da população em idade de trabalhar. No caso dos trabalhadores brancos a taxa de desocupação foi de 10,4\% ficando abaixo da média nacional, enquanto para pretos e pardos manteve-se acima da média, ficando em $17,8 \%$ e $15,4 \%$, respectivamente (IBGE, 2020).

A ideia de que a pandemia atinge a todos indiscriminadamente, que estamos no mesmo barco e precisamos, igualmente, ser imbuídos de um "agir coletivo" em nome da sobrevivência geral é, para dizer o mínimo, ingênua. Sim, o vírus não é uma entidade racional que está em batalha contra um inimigo específico, é apenas um microorganismo se reproduzindo ao encontrar as condições para tal. Ainda assim, não podemos dizer que a contaminação é democrática e indiscriminada. $\mathrm{O}$ acesso a recursos fundamentais para propiciar a hi- 
gienização adequada, o uso de proteção de barreira física - máscara, e as condições objetivas de vida relacionadas à renda e moradia são variáveis que tornam uns mais vulneráveis do que outros.

Isto significa que em países com índices elevados de desigualdade como o Brasil a tendência é de que a pandemia aprofunde o fosso que separa os ricos da chamada classe média e, principalmente, dos mais pobres. Diante do que temos assistido, não é exagero afirmar que o Estado brasileiro está se colocando como um "gestor da morte e do desaparecimento" (SAFATLE, 2020).

O que buscamos indicar é que o fenômeno da pandemia e seus desdobramentos não podem ser compreendidos apartados de suas determinações históricas. Não se trata apenas de uma explicação biológica sobre o comportamento do vírus, mas compreender que a sociedade se encontra mais fragilizada para lidar com este evento em função das escolhas históricas, políticas e econômicas.

A esse respeito, Pochmann (2020) demonstra como a continuidade na adoção da agenda de programas de austeridade fiscal acarretou na fragilização do próprio Estado que se tornou incapaz de responder às necessidades da população em contextos como o atual.

Diante da pandemia governos de extrema direita demonstraram, inicialmente, uma postura negacionista que precisou ser revista para evitar um genocídio. Infelizmente, este não é o caso do governo brasileiro que, por força da posição sustentada inicialmente pelo Ministério da Saúde assume o isolamento social como principal medida para o enfrentamento da pandemia, mas que na sequência recua e apresenta medidas de flexibilização no momento em que a curva de contaminação e mortes encontra-se em ascensão. Preocupado em demasia com a dimensão econômica da crise, inevitável, esquece o governo que economia é feita de pessoas. E não apenas das pessoas que tomam a decisão sobre as diretrizes gerais da política econômica, mas fundamentalmente, de trabalhadores e trabalhadoras que têm vivenciando adoecimento e luto diante da crise sanitária da qual o sistema de saúde público não consegue dar conta em função do desmantelamento ao qual foi submetido pelos sucessivos governos nos últimos anos.

Estes trabalhadores e trabalhadoras estão sendo massacrados pela realidade ao assistir a morte de seus familiares, muitos dos quais 
tiveram acesso negado ou precarizado seu direito ao tratamento adequado à doença em consequência de uma política baseada na visão "fundamentalista do neoliberalismo" (LOWY, 2020).

Como pode o governo considerar que estes trabalhadores e trabalhadoras retornarão às suas atividades laborativas como se nada tivesse acontecido, por que a economia não pode parar? O que torna esta realidade ainda mais dura são famílias sem renda mínima, sem nenhum tipo de emprego e/ou proteção social ou o fato de que pessoas morreram por falta de respiradores. A natureza desta crise coloca à mostra a perversidade do funcionamento do sistema atual e uma saída correta requer, como bem destaca Pochmann (2020) a recuperação do papel do Estado.

É indubitável que a dimensão material da vida, aquilo que permite que trabalhadores e trabalhadoras se reproduzam enquanto tal - o trabalho assalariado - é imediata e urgente. Contudo, não seria correto evitar um descolamento entre as dimensões envolvidas nesta problemática e tratar a crise com a seriedade que ela possui, acoIhendo as pessoas, ofertando o mínimo de condições para que elas possam atravessar este momento?

A partir do exposto nos interessa pensar a repercussão da pandemia nas comunidades terapêuticas (CT), definidas como "entidades que realizam o acolhimento de pessoas, em caráter voluntário, com problemas associados ao uso nocivo ou dependência de substância psicoativa" (SENAD, 2017). São de instituições de natureza privada e, por vezes de matriz religiosa, que se intitulam como promotoras de saúde para usuários de álcool e outras drogas, sendo incluídas na Rede de Atenção Psicossocial (RAPS) através da Portaria GM/MS no 3.088, de 23 de dezembro de 2011, e, atualmente são responsáveis pelo tratamento de inúmeras pessoas nesta situação (IPEA, 2017; CFP, 2018; CFESS, 2018) ${ }^{4}$. Em suma, trata-se de instituições fechadas ou totais para tratamento de pessoas em uso abusivo de substâncias psicoativas (SPA). Possuem, em sua maioria, direcionamento religioso que influencia diretamente a metodologia de trata-

\footnotetext{
${ }^{4}$ A problematização acerca da inserção das comunidades terapêuticas na RAPS para fins de financiamento em detrimento dos serviços públicos de saúde tais como os CAPSad pode ser encontrada em DUARTE (2018), GUIMARÃES; ROSA (2019), PASSOS; GOMES (2019) e não será retomada pelos limites deste texto.
} 
mento baseada no tripé isolamento, trabalho e religião. A despeito dessas características gerais e de possuírem aspectos comuns entre si, cabe destacar que as comunidades terapêuticas brasileiras não podem ser tomadas como um bloco homogêneo sob risco de uma não apreensão ou análise imprecisa de seus significados.

Neste sentido, o presente ensaio teórico tem por objetivo problematizar o funcionamento destes serviços - considerados essenciais pela autoridade sanitária com manutenção das atividades garantidas durante a pandemia - e sua adequação às medidas de segurança e ao protocolo de Manejo Clínico para o novo coronavírus (2019nCoV) publicado pelo Ministério da Saúde (2020). Tais medidas destinam-se aos serviços de saúde e possuem o objetivo de reduzir o nível de contaminação dos indivíduos. Como metodologia realizamos revisão bibliográfica e a seleção do material ocorreu considerando como critérios os autores considerados clássicos e os contemporâneos na área das Ciências Sociais e no campo da Saúde Mental, artigos científicos nacionais, completos e originais publicados nos últimos anos em revistas científicas indexadas e análise documental das legislações vigentes no campo das drogas, em especial a Portaria GM/MS no 340 de 2020, além dos materiais de fiscalização publicadas pelo IPEA (2017) e CFP (2018).

\section{As comunidades terapêuticas no Brasil e às medidas de segurança para o novo coronavírus}

Os primeiros modelos de comunidades terapêuticas remontam às experiências inglesas e estadunidenses, ocorridas no final dos anos de 1940 e início dos anos de 1950 e já se configuraram de diversas maneiras, seja servindo de asilo para pessoas que adoecem psiquicamente ou tratando de pessoas que fazem uso prejudicial de álcool e outras drogas (DE LEON, 2014). No Brasil temos experimentado, desde os anos de 1990, o espraiamento desse segundo tipo: instituições que atuam no campo da saúde mental voltadas à atenção de pessoas em uso prejudicial de substâncias psicoativas. O Relatório recente divulgado pelo IPEA contribui com as tentativas de compreen- 
der estas instituições. Segundo o referido relatório, as comunidades terapêuticas são:

Desenvolvidas e disseminadas a partir de iniciativas não governamen-
tais, estas instituições se organizam em residências coletivas tempo-
rárias, onde ingressam pessoas que fazem uso problemático de dro-
gas, que ali permanecem, por certo tempo, isolados de suas relações
sociais prévias, com o propósito de renunciarem definitivamente ao
uso de drogas e adotarem novos estilos de vida, pautados na absti-
nência de SPAs. Durante sua permanência nas CTs, estas pessoas sub-
metem-se a uma rotina disciplinada, que abrange atividades de tra-
balho e práticas espirituais e/ou religiosas, além de terapias psicológi-
cas, reuniões de grupo de ajuda mútua, entre outras, dependendo
dos recursos financeiros e humanos à disposição de cada CT (2017,
p.8).

Apesar de serem reconhecidas legalmente como opção de serviços voltados à assistência pública de pessoas que fazem uso prejudicial de álcool e drogas pela Lei 13.840/2019, a maioria das comunidades terapêuticas possuem viés religioso (IPEA, 2017) indo na contramão do que se coloca como tendência em relação a serviços dessa natureza em parte da Europa (BARDI, 2019). No ano de 2019 aprovou-se a (nova) Política Nacional sobre Drogas - PNAD, por meio do decreto $n^{\circ}$ 9.761, em substituição da que estava em vigor desde 2002. O novo texto estimula e apoia a expansão das comunidades terapêuticas, inclusive financeiramente. Importante ressaltar que, apesar de terem sido reconhecidos por lei em 2019, estas instituições já integravam a Rede de Atenção Psicossocial (RAPS), desde 2011, por meio da Portaria no 3.088/2011.

O tratamento na maior parte das comunidades terapêuticas se baseia no tripé trabalho, disciplina e espiritualidade: laborterapia ${ }^{5}$ como forma de cuidado e imposição da religião que orienta a instituição - no caso das instituições de natureza religiosa, geralmente evangélicas - combinando, em alguns casos, esses dois pilares com a ade-

\footnotetext{
5 "As equipes identificaram ser comum, na ampla maioria das comunidades terapêuticas visitadas, o uso da chamada "laborterapia", na qual o trabalho seria empregado como ferramenta de disciplina - prática condenada pelos princípios da reforma psiquiátrica estabelecida no Brasil pela Lei no 10.216/2001." (Relatório de Inspeção Nacional em Comunidades Terapêuticas - Conselho Federal de Psicologia, 2018, p. 16).
} 
são de equipes multiprofissionais (IPEA, 2017). Contudo, como demonstra o Relatório de Inspeção do Conselho Federal de Psicologia (2018), que inspecionou 28 comunidades terapêuticas ao redor do Brasil, a presença de equipe profissional não é comum e, quando existe, o vínculo profissional se dá, na maior parte dos casos, por meio de contratos de trabalhos precários. De acordo com o Relatório, a maior parte do serviço prestado advém de trabalho voluntário de fiéis ligados à instituição religiosa responsável e de internos reabilitados. Além disso, o relatório do CFP registrou o uso de punições e castigos físicos aos internos que não se adequam aos preceitos das CTs, além de violação do direito de ir e vir, retenção de pertences pessoais e proibição da comunicação com as famílias (CFP, 2018).

Vale destacar que estas comunidades geralmente se localizam em áreas isoladas, preferencialmente em zonas rurais, seguindo o preceito do isolamento como metodologia de tratamento, afastando as pessoas do território, familiares e de tudo o que possa remeter às circunstâncias de uso da droga. Tal prescrição de tratamento impede o acesso da família aos seus entes internados por um determinado período de tempo, dificultando qualquer tipo de acompanhamento. Por vezes, a família só tem acesso a seus entes nos dias de visita - semanal ou quinzenalmente (IPEA, 2017). Soma-se a isso o fato de que, pela localização ocorrer em áreas isoladas, mesmo após a liberação de visitas, existem dificuldades objetivas com o deslocamento da localidade de moradia até a CT.

A despeito destas questões, ao contrário do que se pode imaginar, o aumento de oferta de vagas públicas nestas instituições tem sido constante, dando sinais da necessidade de pesquisas que busquem conhecer em profundidade estas instituições, o trabalho que realizam e sua eficácia. Ademais, no debate sobre política de drogas no contexto atual é importante estabelecer relação entre o cenário político e a expansão de alternativas conservadoras e religiosas no âmbito da saúde mental à luz dos elementos característicos da formação social brasileira para a compreensão de como chegamos até aqui (GOMES, 2019).

Na perspectiva de ampliação de vagas, as legislações publicadas e aprovadas durante o ano de 2019 foram importantes vetores de estímulo aos editais que foram abertos em todo o território brasi- 
leiro para o financiamento das CT. O Decreto de $n^{\circ} 9.761$ de 11 de abril de 2019, que aprova a Política Nacional Sobre Drogas e revoga o Decreto de n⿳4.345 de 26 de agosto de 2002, que instituiu a Política Nacional Antidrogas, determina em seu art. $3^{\circ}$ que a Secretaria Nacional de Cuidados e Prevenção às Drogas do Ministério da Cidadania e a Secretaria Nacional de Políticas sobre Drogas do Ministério da Justiça e Segurança Pública seriam responsáveis pela articulação e coordenação da implementação da PNAD, no âmbito de suas competências.

A Política Nacional Sobre Drogas de 2019, diferente da Política Nacional Antidrogas de 2002, exclui a redução de danos, estimula a expansão das comunidades terapêuticas como principal estratégia de cuidado e se posicionou contra a descriminalização das drogas. Propõe ainda a regulamentação, avaliação e acompanhamento do tratamento, do acolhimento em CT, da assistência e do cuidado de pessoas que fazem uso prejudicial de álcool e outras drogas lícitas e ilícitas. No que se refere ao tratamento, acolhimento, recuperação, apoio e mútua ajuda no sentido de promover, garantir a articulação e a integração das intervenções para tratamento, recuperação, reinserção social, a comunidade terapêutica aparece listada juntamente a outros serviços públicos que compõe a rede de saúde e de assistência social. Portanto, a Política Nacional Sobre Drogas de 2019 preconiza estimular e apoiar, inclusive financeiramente, o trabalho, o desenvolvimento e estruturação física e funcional das CTs, legitimando-as. No Brasil, as articulações para o financiamento de vagas pelo governo federal nessas instituições só tem aumentado, no último ano o projeto era elevar o número de vagas financiadas para quase $11 \mathrm{mil}$, sob o custo de R\$153,7 milhões por ano ${ }^{6}$.

Neste mesmo cenário de fortalecimento e financiamento dessas instituições, a Organização Mundial da Saúde (OMS) declarou, em 30 de janeiro de 2020, que o surto do novo coronavírus (2019-nCoV) constitui uma Emergência de Saúde Pública de Importância Internacional - ESPII, e o Ministério da Saúde por meio da Portaria no 188, de

\footnotetext{
${ }^{6}$ Matéria disponível em: <https://www.gov.br/mdh/pt-br/assuntos/noticias/2019/marco/ ministros-assinam-documento-que-preve-quase-11-mil-vagas-em-instituicoes-para-dependentes-quimicos>. Acesso em: 09 set. 2020.
} 
3 de fevereiro de 2020, anunciou que o novo vírus constitui Emergência em Saúde Pública de Importância Nacional - ESPIN.

A disseminação do novo coronavírus atingiu a classificação mundial de pandemia e o país adotou medidas no âmbito dos estados, municípios e distrito federal para prevenir essa disseminação, como o isolamento social da população e o funcionamento apenas dos serviços essenciais, além do controle de circulação por meio de restrição aos transportes públicos.

No dia 07 de fevereiro de 2020 foi publicada no Diário Oficial da União a Lei 13.979 que dispõe sobre as medidas para enfrentamento da emergência de saúde pública de importância internacional decorrente do coronavírus responsável pelo surto de 2019. Essa lei determina que para enfrentamento da emergência de saúde pública decorrente do coronavírus, poderão ser adotadas, dentre outras medidas, o isolamento e a quarentena.

O decreto 10.282 de 20 de março de 2020 regulamenta a lei anteriormente citada definindo os serviços públicos e atividades essenciais. Tomando por base o disposto nos itens I e II do artigo $3^{\circ}$ deste decreto, a Portaria GM/MS no 340 de 30 de março de 2020 jus tifica as atividades e serviços oferecidos pelas CT como essenciais, enquadrando-os conforme o ítem I, em serviços de assistência à saúde e conforme o ítem II, serviços de assistência social e atendimento à população em estado de vulnerabilidade.

Essa portaria estabelece medidas para o enfrentamento da Emergência em Saúde Pública de Importância Nacional decorrente de infecção humana pelo novo coronavírus (COVID-19), no âmbito das comunidades terapêuticas. No artigo $4^{\circ}$ determina que as comunidades terapêuticas devem seguir as orientações disponibilizadas pelo Ministério da Saúde no protocolo de manejo clínico para o novo Coronavírus (2019-nCov), e na Cartilha de Orientações para as Comunidades Terapêuticas.

O primeiro documento, protocolo de manejo clínico, tem uma linguagem totalmente direcionada à saúde em um ambiente clínico, sobre informações a respeito de como identificar um caso suspeito de um caso confirmado por exemplo, e também sobre características da infecção, atendimento e tratamento, medidas de prevenção e controle, e notificação. As CT não são instituições clínicas, não con- 
tam com aparelhagem necessária e, em sua maioria, não dispõem de médicos no seu quadro de profissionais obrigatórios.

A Cartilha de Orientações para as Comunidades Terapêuticas disponibilizada pelo Ministério da Cidadania se mostra mais útil por trazer informações básicas sobre o vírus, como ele age, como se dá a sua transmissão, sintomas, prevenção, grupos de risco e orienta a não interrupção do acolhimento na CT durante a pandemia, indicando que se ocorrer ela poderia colocar em risco a vida do usuário, já que, "a dependência química é uma doença crônica, grave e deve ser tratada de acordo com as necessidades clínicas do indivíduo" (2020, p.6)

Da análise dos dois documentos supracitados depreende-se o fortalecimento da ideia de atribuir as CT funções clínicas, uma vez que direciona a esses equipamentos um protocolo de manejo clínico e uma cartilha de orientações que classifica a dependência química como uma doença crônica. Tal atribuição vai na contramão das definições e compreensões sobre a natureza das comunidades terapêuticas presente na legislação brasileira atinente à temática. Nestas, as CT figuram como equipamentos de caráter residencial temporário que precisam trabalhar em articulação com a rede intersetorial de saúde, assistência social, e outras políticas públicas. A própria portaria pontua a necessidade do encaminhamento dos acolhidos para uma Unidade de Saúde em caso de contaminação.

$\mathrm{O}$ artigo $5^{\circ}$ da Portaria GM/MS n 340 trata da não interrupção dos acolhimentos já iniciados, e no caso de contaminação ou suspeita de contaminação o acolhido deve ser encaminhado para atendimento em uma Unidade de Saúde e este acolhido deve receber uma alta administrativa e quando retornar a CT ser incluído novamente na vaga.

No que diz respeito aos novos acolhidos, propõe o isolamento social de 14 dias dentro da instituição e a não oferta de acolhimento às CT que não possuírem condições físicas e recursos humanos para realizar o isolamento. Em caso de suspeita clínico-epidemiológica de infeç̧ão o indivíduo não ficará em isolamento na unidade e nem será acolhido, deverá ser encaminhado a uma Unidade de Saúde, e aqueles que apresentarem exame recente atestando negativo 
para o novo coronavírus estão dispensados do isolamento de 14 dias pré acolhimento.

Dentre as recomendações também está a suspensão das visitas e atividades externas enquanto perdurar a ESPIN decorrente de infecção humana pelo novo coronavírus, o dever da CT de realizar atividades informativas com os acolhidos, a recomendação do encaminhamento a uma Unidade de Saúde a qualquer membro da equipe que apresente sintomas, a suspensão de atividades com pessoas que não façam parte da vida cotidiana e o adiamento de capacitações presenciais no âmbito da Secretaria Nacional de Cuidados e Prevenção às Drogas - SENAPRED.

O Relatório de Inspeção realizado pelo CFP (2018) aponta que estas instituições possuem articulação com os serviços públicos da atenção básica de saúde. Reiteramos aqui a preocupação exposta em texto recente (PASSOS et. al, 2020): como tal articulação ocorre dada as circunstâncias de localização afastada das CT? E mais, em tempos de pandemia, como estão sendo realizadas as medidas de proteção ao contágio e, nos casos de adoecimento, como estão se dando o encaminhamento de possíveis infectados aos serviços emergenciais?

As normativas a respeito das atividades e serviços oferecidos nas comunidades terapêuticas durante a pandemia do novo coronavírus seguem as orientações de isolamento, e cuidado a qual toda a população mundial está sendo orientada. O que o Protocolo de Manejo Clínico promove é o reforço a um isolamento que já estava estabelecido, uma vez que ele é assumido como uma das condições para a admissão nas CT. Contudo, ao suspender visitas familiares e outras interações com o mundo externo (medidas necessárias em função da pandemia) quais as repercussões emocionais, psíquicas e sociais para as pessoas que se encontram internadas nestas instituições?

Ao nos referirmos aos internos nas CT estamos fazendo menção às pessoas que já estavam em isolamento social, apresentavam acometimentos psicológicos antes da pandemia e que agora fazem parte do público que está de fora de grande parte das medidas tomadas para uma tentativa de melhorar a qualidade de vida da popula- 
ção, como publicações de orientações ${ }^{7}$, entretenimento ${ }^{8}$, atendimentos psicológicos online gratuito ${ }^{9}$, assistência financeira emergencial. Adicionalmente, estes usuários encontram-se sem a possibilidade de visita dos familiares, o que representa uma ruptura total com o ambiente externo ao do tratamento. Chamamos atenção para a necessidade de não homogeneizar as formas de isolamento contidas neste contexto como idêntica em natureza, significado e repercussões: o isolamento social em função da pandemia na residência de moradia com familiares é distinto daquele realizado em ambiente institucional sem perspectiva de contato com estes. Em decorrência, indagamos se estas questões são fonte de preocupação para o trabalho realizado pelas $\mathrm{CT}$ e, em caso positivo, de que forma estão sendo abordadas na relação com os usuários e familiares? Está sendo estabelecido algum acompanhamento voltado à saúde mental destes usuários em função do atual cenário?

\section{Isolamento social e confinamento como estratégias de (des)proteção}

Em estudo sobre situações de quarentena, Brooks (2000) demonstra a alta prevalência de efeitos psicológicos negativos, especialmente humor rebaixado e irritabilidade, ao lado de raiva, medo e insônia, muitas vezes de longa duração como resultados frequentes desta situação de confinamento. Toda a metodologia de trabalho das CT se sustenta no princípio do isolamento físico e social como condição para o tratamento que, por sua vez, é baseado na abstinência.

De acordo com Goffman (2008), ocorre uma a influência das instituições totais no comportamento humano. As instituições assumem seu caráter total quando submetem seus internos a realizar suas ações num mesmo lugar, com um mesmo grupo de pessoas e sob tratamento, obrigações e regras iguais para a realização de atividades impostas, retirando do indivíduo características que são as dis-

\footnotetext{
${ }^{7}$ Como por exemplo, citamos as Cartilhas lançadas pelo Centro de Estudos e Pesquisas em Emergências e Desastres em Saúde (CEPEDES/ FIOCRUZ).

${ }^{8}$ Como por exemplo citamos as lives e entretenimentos através da televisão e internet.

${ }^{9}$ Como por exemplo citamos o atendimento online gratuito disponibilizado pelos Institutos de Psicologia da UERJ e da USP.
} 
tintas formas de agir dependendo do lugar, da companhia e sob diferentes autoridades. Imposições de comportamentos que interfiram na autonomia e liberdade de ação de indivíduos estão diretamente relacionadas ao "desequilíbrio do eu" (GOFFMAN, 2008).

Dentro das CT o mesmo ocorre quando os indivíduos são submetidos a rotinas impostas de laborterapia e espiritualidade, este último apropriado de maneira controversa por parte das CT que interpretam a espiritualidade como religiosidade, impondo a participação em rituais que acreditam ser parte do tratamento para o alcance da abstinência, conferindo direcionamento moral a uma questão de saúde pública.

As comunidades terapêuticas brasileiras se revelam como uma das instituições sociais que buscam moldar corpos, comportamentos, subjetividades e identidades a fim de que se tornem aptos para viver em sociedade e para a sujeição à produção voltada ao capitalismo (PEREIRA; PASSOS, 2017). Nessa sociedade que o indivíduo vale o que produz, quanto vale aquele que, devido ao uso prejudicial de álcool e outras drogas, se mostra incapacitado de produzir no ritmo e padrão socialmente estabelecido?

Uma das respostas sociais tem sido a legitimação do controle desses corpos e subjetividades mantidos em isolamento sob normas rígidas de comportamento geralmente atreladas a imposições religiosas, infringindo direitos básicos como o artigo $5^{\circ}$ da Constituição Federal brasileira que garante ser inviolável a liberdade de consciência e de crença. A institucionalização dos sujeitos considerados "marginais" seja como medida de reabilitação funcional ao processo de produção social, seja como forma de invisibilizá-lo é histórica e constituise uma forma de violência.

A violência expressa no controle desses corpos e subjetividades é componente fundante no modo de produção capitalista e representa uma fonte de lucros, além de ser uma das estratégias de dominação, submissão e contenção dos indesejáveis. No caso das comunidades terapêuticas é preciso inserir no contexto histórico e territorial a função social dessas instituições ao enquadrar pessoas consideradas "desviantes" atualizando a prática da institucionalização: qual a eficácia deste tipo de tratamento? Que ganhos estão envolvidos no controle desses corpos? 
Com relação ao controle da pandemia, no caso brasileiro é importante ter nítido, como destaca Pochmann (2020) os elementos históricos que contribuem na compreensão da forma de enfrentamento adotada pelo atual governo. A história de nossa formação social caracterizada pela associação do novo ao arcaico, do capitalismo à escravidão ensina que nos acostumamos com um Estado que trata de forma distinta as pessoas, como se houvessem duas categorias para as quais vida e morte têm significados sociais e simbólicos diferentes, a saber: pessoas tratadas como pessoas e outras como coisas. Ou como já apontava Fanon (2008), os que estão na zona do ser e os da zona do não ser. Os que estão na zona do não ser, nesta conjuntura, são números, baixas inevitáveis seguindo a lei do mais forte segundo a perspectiva a-histórica que impera entre os que conduzem a gestão da necropolítica no país. Contudo, estas pessoas possuem nome, sobrenome, identidade, gênero, raça/cor.

Essa problemática contribui na análise da disseminação de medidas disciplinares nas CT como forma de tratamento para pessoas em uso prejudicial de SPA. Trata-se de uma metodologia histórica de tratamento que recupera a base fundamental do tratamento moral ao qual, na atualidade, se adicionam elementos religiosos.

Portanto, isolamento, contenção, uso indevido e indiscriminado de medicação psiquiátrica, punições estão entre as medidas que compõem a metodologia de tratamento de algumas CT. Cabe lembrar que parte significativa que busca por atendimento na rede pública de saúde é composta pelo grupo já estigmatizado e oprimido em nossa sociedade. Historicamente, sãos estes os corpos e subjetividades que têm sido submetidos ao controle e sujeição do Estado e, novamente, são os que mais tem sofrido os impactos da pandemia atual, dentro ou fora das CT.

\section{Considerações finais}

A pandemia do novo coronavírus promoveu mudanças que influenciarão os próximos anos. Até que se tenha uma vacina contra a doença, diversas medidas deverão ser aplicadas e uma nova forma de socialização estabelecida. Nesta, as expressões da questão social am- 
plificam-se, explicitando a maior vulnerabilidade da população negra e periférica.

Neste sentido, é preciso compreender melhor a natureza e eficácia das comunidades terapêuticas e sua atuação em meio ao que vem se construindo enquanto espaço de "cuidado" e atenção em saúde mental, inclusive, na pandemia. Uma vez que são consideradas pelo Ministério da Saúde como estabelecimentos de saúde, aprofundar o debate acerca capacidade de adequação sanitária das CT tornase de suma importância. Neste particular, não consideramos possível apresentar conclusões, mas indicar algumas inquietações que demandam acompanhamento dos que estudam a temática.

As CT já praticavam o isolamento social como parte do tratamento, reproduzindo em alguns casos uma lógica manicomial, aprisionando corpos majoritariamente negros e pobres. Como tais instituições estão lidando com a pandemia em curso no país? Que adaptações foram realizadas? Sabe-se, por exemplo e em função de fiscalizações pregressas, da falta equipe técnica especializada para realizar os protocolos básicos e o manejo clínico necessário. $O$ endurecimento do isolamento dos internos nas CT em função da pandemia tem influenciado na eficácia do tratamento? As repercussões estão sendo monitoradas pela equipe? Houve aumento no número de evasão?

A todos nós cabe apenas uma certeza e um punhado de dúvidas: a certeza refere-se a assertiva de Prashad ao afirmar que "não voltaremos ao normal porque o normal era o problema" (2020). As dúvidas se referem a se as mudanças exigidas nos levarão a uma sociedade com menos opressão/exploração e mais justiça social ou se fará recrudescer a faceta mais vil desta organização social.

\section{Referências}

BARDI, G. Entre a "cruz" e a "caldeirinha": doses diárias de alienação nas comunidades terapêuticas religiosas". 2019. Tese (Doutorado em Política Social). Programa de Pós-Graduação em Política Social do Centro de Ciências Jurídicas e Econômicas da Universidade Federal do Espírito Santo. Vitória, 2019. 
BOITEUX, L. Liberdades individuais, direitos humanos e a internação forçada em massa de usuários de drogas. Revista Brasileira de Estudos Constitucionais, Belo Horizonte, v. 7, no 25, p. 53-80, jan./abr. 2013.

BRASIL. Decreto N. 4.345, de 27 de setembro de 2006. Regulamenta a Lei N. 11.343, de 23 de agosto de 2006, que trata das políticas públicas sobre drogas e da instituição do Sistema Nacional de Políticas Públicas sobre Drogas - SISNAD, e dá outras providências. Disponível em: <http://www.planalto.gov.br/ccivil_03/_Ato2004-2006/2006/ Decreto/D5912.htm>. Acesso em: 06 maio 2020.

. Decreto n. 9.761, de 11 de abril de 2019. Aprova a Política Nacional Sobre Drogas. Disponível em: <http:// www.planalto.gov.br/ccivil_03/_ato2019-2022/2019/Decreto/ D9761.htm>. Acesso em: 06 maio 2020.

. Decreto n. 10.282, de 20 de março de 2020. Regulamenta a Lei n. 13.979, de 6 de fevereiro de 2020, para definir os serviços públicos e as atividades essenciais. Disponível em: <http://www.planalto.gov.br/ccivil_03/_ato2019-2022/2020/decreto/D10282.htm>. Acesso em: 16 jun. 2020.

. Lei n. 13.979, de 6 de fevereiro de 2020. Dispõe sobre as medidas para enfrentamento da emergência de saúde pública de importância internacional decorrente do coronavírus responsável pelo surto de 2019. Disponível em: <http://www.in.gov.br/en/web/ dou/-/lei-n-13.979-de-6-de-fevereiro-de-2020-242078735>. Acesso em: 16 jun. 2020.

. Lei n. 11.343, de 23 de agosto de 2006. Institui o Sistema Nacional de Políticas Públicas sobre Drogas - Sisnad; prescreve medidas para prevenção do uso indevido, atenção e reinserção social de usuários e dependentes de drogas; estabelece normas para repressão à produção não autorizada e ao tráfico ilícito de drogas; define crimes e dá outras providências. Disponível em: <http://www.planalto.gov.br/ccivil_03/_ato2004-2006/2006/lei//11343.htm>. Acesso em: 06 maio 2020. 
. Lei n. 13.840, de 5 de junho de 2019. Altera as Leis ns.

11.343, de 23 de agosto de 2006, 7.560, de 19 de dezembro de 1986, 9.250, de 26 de dezembro de 1995, 9.532, de 10 de dezembro de $1997,8.981$, de 20 de janeiro de 1995, 8.315, de 23 de dezembro de $1991,8.706$, de 14 de setembro de 1993, 8.069, de 13 de julho de $1990,9.394$, de 20 de dezembro de 1996, e 9.503, de 23 de setembro de 1997, os Decretos-Lei nos 4.048, de 22 de janeiro de 1942, 8.621, de 10 de janeiro de 1946, e 5.452, de 10 de maio de 1943, para dispor sobre o Sistema Nacional de Políticas Públicas sobre Drogas e as condições de atenção aos usuários ou dependentes de drogas e para tratar do financiamento das políticas sobre drogas. Disponível em: <http://www.planalto.gov.br/ccivil_03/_ato2019-2022/2019/lei/ L13840.htm>. Acesso em: 06 maio 2020.

. Portaria GM/MS n. 340, de $\mathbf{3 0}$ de março de 2020. Estabelece medidas para o enfrentamento da Emergência em Saúde Pública de Importância Nacional decorrente de infecção humana pelo novo coronavírus (COVID-19), no âmbito das comunidades terapêuticas. Disponível em: <http://www.in.gov.br/en/web/dou/-/portaria-n-340de-30-de-marco-de-2020-250405535>. Acesso em: 16 jun. 2020.

. Portaria GM/MS n. 3.088, de 23 de dezembro de 2011. Institui a Rede de Atenção Psicossocial para pessoas com sofrimento ou transtorno mental e com necessidades decorrentes do uso de crack, álcool e outras drogas, no âmbito do Sistema Único de Saúde (SUS). Disponível em: <http://bvsms.saude.gov.br/bvs/saudelegis/gm/ 2011/prt3088_23_12_2011_rep.html>. Acesso em: 16 jun. 2020.

- Ministério da Saúde. Protocolo de manejo clínico para o novo coronavírus (2019-nCoV). Disponível em: <https://portalarquivos2.saude.gov.br/images/pdf/2020/fevereiro/11/protocolo-manejocoronavirus.pdf>. Acesso em: 16 jun. 2020.

. Ministério da Cidadania. Coronavírus: cartilha de orientação para as comunidades terapêuticas. Disponível em: <http://antigo.desenvolvimentosocial.gov.br/imprensa/Noticias/comunidades-terapeuticas-recebem-diretrizes-para-atuacao-no-periodo-de-combateao-covid-19/cartilha_comunidades_terapeuticas.pdf $>$. Acesso em: 16 jun. 2020. 
BROOKS, S. K., et al. The psychological impact of quarantine and how to reduce it: rapid review of the evidence. The Lancet, v. 395, n. 10227, p. 912-920, march, 2020.

CFESS. Relatório de fiscalização: Serviço Social e a inserção de assistentes sociais nas comunidades terapêuticas no Brasil. Brasília: CFESS, 2018. Disponível em: < http://www.cfess.org.br/arquivos/RelatorioCFESS-ComunidadesTerapeuticas2018-Site.pdf>. Acesso em: 09 set. 2020.

CONSELHO FEDERAL DE PSICOLOGIA - CFP. Relatório da inspeção nacional em comunidades terapêuticas. Disponível em: $<$ http://site.cfp.org.br/wp-content/uploads/2018/06/Relat\%C3\%B3rio-da-Inspe\%C3\%A7\%C3\%A3o-Nacional-em-Comunidades-Terap\%C3\%AAuticas.pdf>. Acesso em: 06 maio 2020.

DE LEON, G. A comunidade terapêutica: teoria, modelo e método. São Paulo: Loyola, 2003.

DUARTE, M. J. de O. Política de saúde mental e drogas: desafios ao trabalho profissional em tempos de resistência. Libertas, Juiz de Fora, v.18, n. 2, p. 227-248, ago./dez., 2018.

FANON, F. Pele negra, máscara branca. Salvador: EDUFBA, 2008.

FOUCAULT, M. Vigiar e punir: história da violência nas prisões. Petrópolis: Editora Vozes, 1987.

FUNDAÇÃO INSTITUTO OSWALDO CRUZ - FIOCRUZ. Em duas semanas, número de negros mortos por coronavírus é cinco vezes maior no país. Informe ENSP, Rio de Janeiro, 11 de maio de 2020. Disponível em: <http://www.ensp.fiocruz.br/portal-ensp/informe/site/materia/detalhe/48879>. Acesso em: 27 maio 2020.

GOFFMAN, E. Manicômios, prisões e conventos. São Paulo: Editora Perspectiva, 2008.

GOMES, T. Reforma psiquiátrica e formação sócio-histórica brasileira: elementos para o debate. Argumentum, Vitória, v. 10, n.3, p. 24-34, set./dez. 2018.

GUIMARÃES, T. A. A.; ROSA, L. C. S. A remanicomialização do cuidado em saúde mental no Brasil no período de 2010-2019: análise de uma 
conjuntura antirreformista. $\mathbf{O}$ social em questão, Rio de Janeiro, ano XXII, n. 44, mai./ago., 2019.

Instituto Brasileiro de Geografia e Estatística - IBGE. Pesquisa Nacional por Amostra de Domicílios Contínua (PNAD). Disponível em <https://www.ibge.gov.br/estatisticas/sociais/trabalho/9173-pesquisa-nacional-por-amostra-de-domicilios-continua-trimestral.html? $\mathrm{t}=$ resultados $>$. Acesso em: 08 set. 2020.

INSTITUO DE PESQUISA ECONÔMICA APLICADA - IPEA. Perfil das comunidades terapêuticas brasileiras. Disponível em: < http://www.ipea.gov.br/portal/images/stories/PDFs/nota_tecnica/ 20170418_nt21.pdf>. Acesso em: 08 maio 2020.

LOWY. M. O neofascista Bolsonaro diante da pandemia. Blog da Boitempo, São Paulo, 28 de abril de 2020. Disponível em: <https://blogdaboitempo.com.br/2020/04/28/michael-lowy-o-neofascista-bolsonaro-diante-da-pandemia/>. Acesso em: 09 set. 2020.

MUSSE, L. B. Internações forçadas de usuários e dependentes de drogas: controvérsias jurídicas e institucionais. In: SANTOS, M. P. G (Org.). Comunidades terapêuticas: temas para reflexão. Rio de Janeiro: IPEA, 2018.

PASSOS, R. G. "A carne mais barata do mercado é a negra": saúde da população negra em tempos de COVID-19. In: MOREIRA, E. et. al. (Org.). Em tempos de pandemia: propostas para a defesa da vida e de direitos sociais. Rio de Janeiro: UFRJ, Centro de Filosofia e Ciências Humanas, Escola de Serviço Social, 2020.

PASSOS, R. G.; ARAÚJO, G. C. L.; GOMES, T. M. S.; FARIAS, J. S. Comunidades terapêuticas e a (re)manicomialização na cidade do Rio de Janeiro. Argumentum, Vitória, v. 12, n. 2, p. 125-140, maio/ago., 2020.

PEREIRA, M. O.; PASSOS, R. G. Desafios contemporâneos na luta antimanicomial: comunidades terapêuticas, gênero e sexualidade. In: PEREIRA, M. O.; PASSOS, R. G. Luta antimanicomial e feminismos: discussões de gênero, raça e classe para a reforma psiquiátrica brasileira. Rio de Janeiro: Editora Autografia, 2017. 
PRASHAD, V. Não voltaremos ao normal porque o normal era o problema. Brasil de Fato, São Paulo, 30 de março de 2020. Disponível em: <https://www.brasildefato.com.br/2020/03/30/nao-voltaremosao-normal-porque-o-normal-era-o-problema>. Acesso em: 04 abr. 2020.

POCHMANN, M. Pandemia expõe que governo não sabe o que é um pobre ou a economia real. [Entrevista concedida a] André Barrocal. Carta Capital, São Paulo, 01 de abril de 2020. Disponível em: <https://www.cartacapital.com.br/politica/pandemia-expoe-quegoverno-nao-sabe-o-que-e-um-pobre-ou-a-economia-real/>. Acesso em: 15 abr. 2020.

SAFATLE, V. Bem-vindo ao Estado suicidário. São Paulo: $n-1$ edições, 2020. Disponível em: <https://n-1edicoes.org/004>. Acesso em: 09 set. 2020.

SECRETARIA NACIONAL DE POLÍTICAS SOBRE DROGAS - SENAD. Comunidades terapêuticas: história e regulamentação. Disponível em: <http://www.aberta.senad.gov.br/medias/original/ 201706/20170605-134703-001.pdf>. Acesso em: 20 jul. 2020. 